\title{
Hypertensive urgencies during the first wave of the COVID-19 pandemic in a tertiary hospital setting: a U-shaped alarming curve
}

\author{
Ioannis Leontsinis ${ }^{1}$, Vasilios Papademetriou ${ }^{2}$, Christina Chrysohoou ${ }^{1}$, Maria Kariori ${ }^{1}$, \\ Ioannis Dalakouras ${ }^{1}$, Panayotis Tolis ${ }^{1}$, Christos Fragoulis ${ }^{1}$, Theodoros Kalos ${ }^{1}$, \\ Fotios-Panagiotis Tatakis ${ }^{1}$, Kyriakos Dimitriadis ${ }^{1}$, Michael Doumas ${ }^{3}$, Helen Sambatakou, \\ Maria Pirounaki ${ }^{5}$, Constantinos Mihas ${ }^{1}$, Niki Katsiki ${ }^{6,7}$, Sonu Bhaskar ${ }^{8}$, Georgios Tsivgoulis ${ }^{9}$, \\ Dimitrios Tousoulis ${ }^{1}$, Maciej Banach ${ }^{10,11,12}$, Konstantinos Tsioufis ${ }^{1}$
}

${ }^{1}$ First Cardiology Clinic, School of Medicine, National and Kapodistrian University of Athens, Athens, Greece

${ }^{2}$ Cardiology Department, Georgetown University and Veterans Affairs Medical Center, Washington, District of Columbia, USA

${ }^{3}$ Second Propedeutic Department of Internal Medicine, Medical School, Aristotle University of Thessaloniki, Hippokration Hospital, Thessaloniki, Greece

${ }^{4}$ Second Department of Internal Medicine, HIV Unit, Hippokration General Hospital, Medical School, National and Kapodistrian University of Athens, Athens, Greece ${ }^{5}$ Department of Internal Medicine, Hippokration General Hospital, Athens, Greece ${ }^{6}$ Department of Nutritional Sciences and Dietetics, International Hellenic University, Athens, Greece

${ }^{7}$ School of Medicine, European University Cyprus, Nicosia, Cyprus

${ }^{8}$ Department of Neurology, Liverpool Hospital and South Western Sydney Local Health District, Sydney, NSW, Australia

${ }^{9}$ Second Department of Neurology, Attikon Hospital, National and Kapodistrian University of Athens, School of Medicine, Athens, Greece

${ }^{10}$ Department of Hypertension, Medical University of Lodz (MUL), Lodz, Poland

${ }^{11}$ Polish Mother's Memorial Hospital Research Institute (PMMHRI), Lodz, Poland

${ }^{12}$ Cardiovascular Research Centre, University of Zielona Gora, Zielona Gora, Poland

Submitted: 11 March 2021; Accepted: 13 August 2021

Online publication: 23 September 2021

Arch Med Sci 2022; 18 (4): 982-990

DOI: https://doi.org/10.5114/aoms/141243

Copyright @ 2022 Termedia \& Banach

\section{Abstract}

Introduction: The coronavirus disease 2019 (COVID-19) pandemic provoked unprecedented disturbance in hypertension care, while alarming concerns arose about its long-term consequences. We investigated the trends of emergency visits and admissions regarding uncontrolled hypertension in order to assess the impact of COVID-19 spread on population behavior towards hypertension urgencies during its first wave.

Material and methods: Data from daily unscheduled visits and admission counts in the Cardiology sector were collected from the Emergency Department database of a tertiary General Hospital in Athens, Greece for the period January $15^{\text {th }}$ to July $15^{\text {th }} 2020$. These data were compared with those from the previous year. Cases of patients who presented with hypertensive urgency or who were admitted due to uncontrolled hypertension were separately analyzed.

Results: A total of 7,373 patient records were analyzed. Hypertension urgency cases demonstrated a U-shaped distribution in 2020, showing a declining trend during the rapid virus spread, an image that was reversed after the transmission rate's decline. COVID-19 incidence in Greece was inversely associated with uncontrolled hypertension admissions during its declining phase $(r=-0.64, p=0.009)$, whereas to-

\section{Corresponding author:} Konstantinos Tsioufis MD, $\mathrm{PhD}$ Hippokration Hospital First Cardiology Clinic School of Medicine University of Athens 114 Vass Sofias Ave 11528 Athens, Greece Phone: (+30) 2132088099 Fax: (+30) 2132088676 E-mail: ktsioufis@hippocratio.gr 
tal attendance exhibited a similar correlation during the first and the following months of the pandemic $(r=0.677, p=0.031, r=-0.789, p=0.001)$. Uncontrolled hypertension rate on admission was positively related to the national incidence of COVID-19 cases during the first months of $2020(r=0.82, p=0.045)$.

Conclusions: Hypertensive urgency-related visits followed a U-shape distribution during the pandemic's first wave with the attendance nadir coinciding with the virus spread peak. This is a complex phenomenon, closely related to increased levels of public stress, disruptions in health care services and to a lesser extent to the imposed restrictions in transportation. The initial relative increase in uncontrolled hypertension-related admissions rate, combined with the later increase of hypertensive urgencies may be indicative of blood pressure deregulation among the studied population, which is multifactorial and potentially detrimental.

Key words: coronavirus disease 2019, uncontrolled hypertension, hypertension urgency, blood pressure.

\section{Introduction}

In the era of the COVID-19 pandemic, the management of non-communicable diseases (NCDs) becomes challenging. The World Health Organization (WHO) reported significant disruptions in NCD-related services due to the virus spread. Dental care, rehabilitation and palliative care appeared to be the most affected domains as shown in a survey of 163 countries [1]. Nevertheless, the management of other NCDs such as hypertension (HTN), diabetes and cancer suffered similar disturbances [1]. National health systems around the world responded to this invisible threat by employing adjustments to the health care system including cancellations of elective procedures and outpatient visits. Part of the available resources was shifted to support the increased demand for inpatient care or to control viral transmission. On the other hand, patient attendance at hospitals showed a significant decline. The fear of potential contagion was identified as the main cause for this population behavior [2-5]. These changes in medical services along with the patients' feeling of insecurity limited the global effort to control NCDs.

The HTN community experienced additional COVID-19-related stress and uncertainties. Hypertensive patients appeared to be more susceptible to the virus than normotensives ones and uncontrolled HTN was associated with worse disease outcomes [6-14]. Contradictory reports regarding renin-angiotensin system (RAS) blockers $[15,16]$ created additional confusion to the public, which according to a recently published survey among centers of excellence of the European Society of Hypertension (ESH) prompted part of the population to discontinue treatment [17]. Increased anxiety and treatment discontinuation can adversely affect blood pressure (BP) control, reflecting on the incidence of hypertensive urgencies ( $\mathrm{HTNu}$ ) and emergencies (HTNe). HTNu are usually defined as acute episodes of marked BP rise and differ from HTNe events as they are not related to evidence of new target organ damage and they are frequently asymptomatic $[18,19]$. These episodes account for a large percentage of the total visits to the emergency department, being also linked to increased morbidity and mortality [18-23].

The aim of the present study was to investigate the population behavior regarding HTNu during the first wave of the COVID-19 pandemic.

\section{Material and methods}

This study is an observational, retrospective analysis of unscheduled visits for HTNu in the Emergency Cardiology Department (ECD) of a tertiary University General Hospital in the metropolitan area of Athens, Greece. Under normal circumstances, outpatient HTN care in this hospital has been provided by two HTN clinics and one center of excellence, accommodating more than 5000 scheduled visits per year. The study period was set to include the first wave of the COVID-19 pandemic and ranged between January $15^{\text {th }}$ and July $14^{\text {th }}, 2020$. The findings were compared with the respective period of the previous year. The first confirmed COVID-19 case in Greece was reported on February $26^{\text {th }}, 2020$, whereas a complete lockdown was imposed on March $10^{\text {th }}$, 2020. During the study period, the hospital remained open to the public for general emergencies and it was not limited to COVID-19 infected patients. On the contrary, it was not dedicated to hospitalized confirmed COVID-19 cases. The study period was intentionally selected to start prior to the coronavirus spread in Greece and to include several months after the cancellation of the restrictive measures, which happened on May $4^{\text {th }}, 2020$. Population behavior towards hypertensive urgencies was evaluated upon the trends of unscheduled visits for uncontrolled hypertension during the aforementioned period which were compared with the ones of the previous year.

The study was carried out following standard ethics requirements according to the Helsinki Declaration with the permission of the hospital's Bioethics Committee (ref number 3521, May 2020).

Data were retrieved from the ECD visitor's registry. All unscheduled visits during the study period were extracted and discriminated by sex, age, reason for visit, initial diagnosis and outcome. The three different outcomes of interest were hospi- 
I. Leontsinis, V. Papademetriou, C. Chrysohoou, M. Kariori, I. Dalakouras, P. Tolis, C. Fragoulis, T. Kalos, F.P. Tatakis, K. Dimitriadis, M. Doumas, H. Sambatakou, M. Pirounaki, C. Mihas, N. Katsiki, S. Bhaskar, G. Tsivgoulis, D. Tousoulis, M. Banach, K. Tsioufis

tal admission, death in ECD and discharge. For the present study, all patients with HTNu or diagnosis of HTN on admission were analyzed separately. HTNu was defined according to the current European Society of Cardiology/European Society of Hypertension (2018 ESC/ESH) guidelines [20]. HTN diagnosis on admission refers to cases admitted to the hospital due to uncontrolled HTN, taking or not taking antihypertensive medication.

\section{Statistical analysis}

All categorical variables are shown as absolute and relative (\%) frequencies, while the age variable is shown as mean \pm standard deviation (SD). Visits are presented as counts. For the purposes of this analysis, the ratio of HTN diagnoses on admission was calculated as the number of patients with HTN diagnoses/total incidents per time period. Pearson's $\chi^{2}$ and Student's $t$-test statistics were used for simple bivariate comparisons, depending on the type of variable. Time-series analysis using Poisson function and linear trend modeling were conducted in order to evaluate the pattern of admissions and visits by time periods (weeks or halfmonth periods). To further investigate the pattern, other non-linear trends (parabolic and polynomial) were also tested. Cross-correlation analysis was also applied between the national COVID-19 confirmed cases and visits at the ECD from February $26^{\text {th }}$ (the first confirmed case in Greece) to July $15^{\text {th }}, 2020$. All tested hypotheses were two-sided at a significance value of $p<0.05$. All statistical analyses were performed using the Stata SE 16 software (STATA Corp Ltd., Texas, USA).

\section{Results}

A total of 7,373 patients records were used for this study. The descriptive characteristics of the participants are shown in Table I. Admissions to the hospital for uncontrolled HTN and cases of HTNu during the first wave of the COVID-19 pandemic were compared with the respective events during the same period of the previous year. Overall distribution of gender and course was different between 2019 and 2020. A higher percentage of women (43.5\%) visited the ECD during the first months of 2020 compared with 2019 (41.1\%) $(p=0.035)$. The relative frequency of all-cause admissions during the period between January $15^{\text {th }}$ and July $15^{\text {th }}$, 2020 was significantly higher than the corresponding frequency during the same period in 2019 (i.e., 47.4 vs. $43.8 \%, p=0.007$ ) (Figure 1). The overall mean age of admitted patients was $64.1 \pm 18.1$ years and it was similar between patients admitted in 2020 and 2019 ( $p=0.856)$. Moreover, there were no differences in the pattern of reason for visit to the ECD (HTNu vs. other) (Figure 2) or the final diagnosis ( $p=0.397$ and 0.612 , respectively).

The number of patient visits at the ECD with HTNu demonstrated a U-shaped pattern during the first months of 2020 ( $p=0.001$ ) (Figure 3), following a quadratic non-linear trend. This pattern was not observed during the similar period of 2019 ( $p=0.707)$. More specifically, there was a significant reduction in cases from January $15^{\text {th }}$ to April $15^{\text {th }}, 2020$, when the COVID-19 cases increased in Greece ( $p$ for linear trend $=0.045$, Figure 3 ).

In contrast, a significant increase was reported from April $15^{\text {th }}$ to July $15^{\text {th }}, 2020$, when the national COVID-19 cases decreased and remained low for a period of time ( $p$ for linear trend $=0.030$ ) (Figure 4). Such trends did not appear during the same time periods of 2019 ( $p=0.480$ and 0.514 , respectively).

In cross-correlation analysis a significant inverse association was observed between the num-

Table I. Descriptive statistics of the study population

\begin{tabular}{|c|c|c|c|c|c|c|}
\hline \multirow[t]{2}{*}{ Parameter } & & \multicolumn{2}{|c|}{ Jan $15^{\text {th }}-$ Jul $15^{\text {th }} 2019$} & \multicolumn{2}{|c|}{ Jan $15^{\text {th }}-J u l 15^{\text {th }} 2020$} & \multirow[t]{2}{*}{$P$-value } \\
\hline & & $n$ & $\%$ & $n$ & $\%$ & \\
\hline \multirow[t]{2}{*}{ Gender } & Men & 2377 & 58.9 & 1885 & 56.5 & 0.035 \\
\hline & Women & 1658 & 41.1 & 1453 & 43.5 & \\
\hline \multirow[t]{2}{*}{ Reason for ECD visit } & $\mathrm{HTNu}$ & 193 & 5.0 & 175 & 5.5 & 0.397 \\
\hline & Other & 3635 & 95.0 & 3010 & 94.5 & \\
\hline \multirow{2}{*}{$\begin{array}{l}\text { Diagnosis on } \\
\text { hospital admission }\end{array}$} & HTN & 224 & 6.0 & 178 & 5.7 & 0.612 \\
\hline & Other & 3532 & 94.0 & 2958 & 94.3 & \\
\hline \multirow[t]{3}{*}{ Outcome } & Admission & 1702 & 43.8 & 1556 & 47.4 & 0.007 \\
\hline & No admission & 2142 & 55.1 & 1686 & 51.4 & \\
\hline & Death & 44 & 1.1 & 38 & 1.2 & \\
\hline Parameter & & Mean & SD & Mean & SD & \\
\hline Age [years] & & 64.1 & 18.4 & 64.2 & 17.6 & 0.856 \\
\hline
\end{tabular}

ECD - emergency department, HTN - hypertension, HTNu - hypertension urgency, SD - standard deviation. 


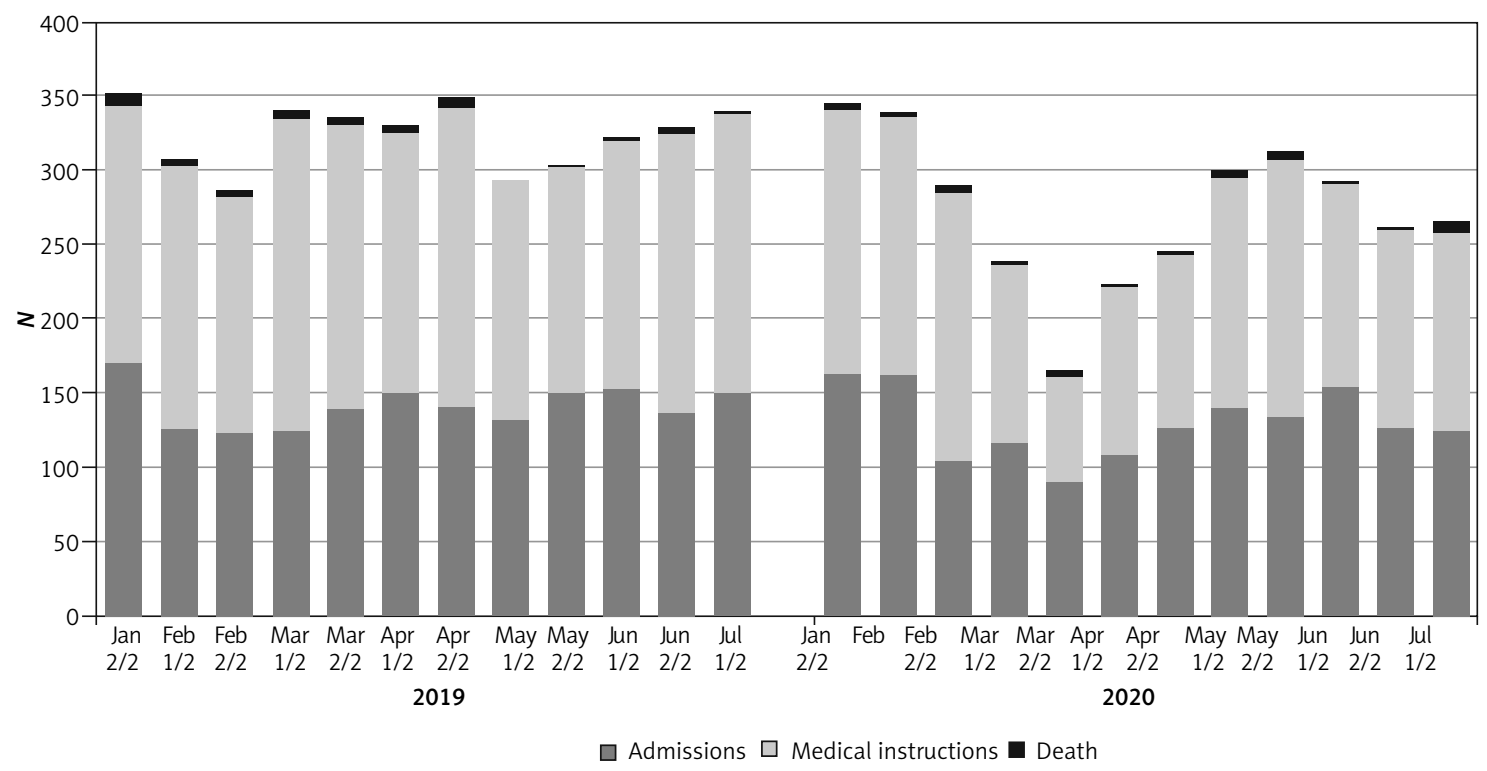

Figure 1. Distribution of the outcomes after the visits of patients in the emergency department of a tertiary hospital in Athens, Greece, during January-July (in 2019 and 2020, respectively)

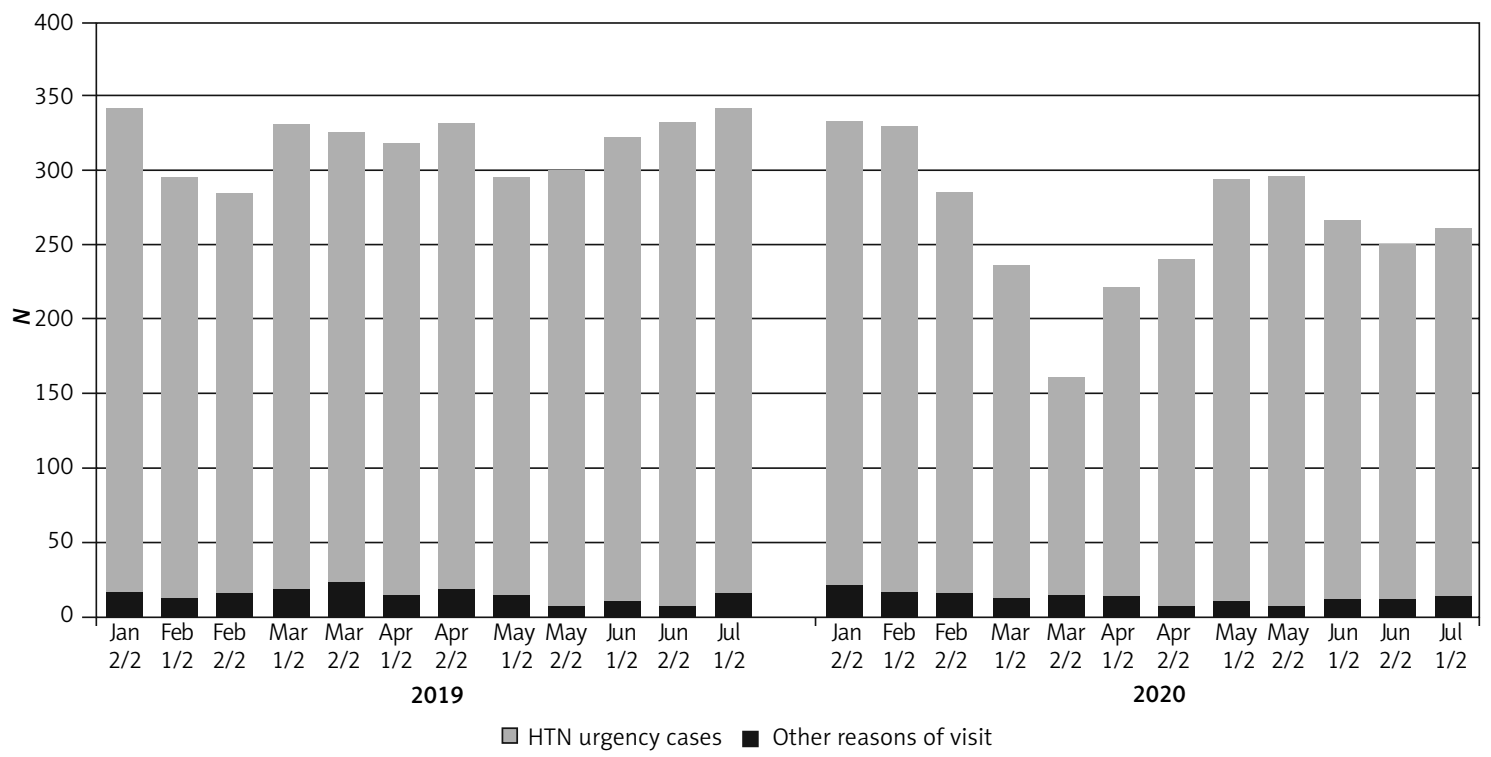

Figure 2. Distribution of the presenting reasons for visits in the emergency department of a tertiary hospital in Athens, Greece, during January-July (2019-2020)

HTN - hypertension.

ber of confirmed national COVID-19 cases and the HTN related admissions to our hospital, i.e., as the number of COVID-19 cases declined, the number of admissions increased $(r=-0.64$, lag 7 days, $p=0.009$ ). The same type of inverse association was evident between the number of COVID-19 cases and the number of total visits both during the increase (from Feb $26^{\text {th }}$ to April $2^{\text {nd }}, 2020$ ) and during the decrease (April $3^{\text {rd }}$ to July $15^{\text {th }}, 2020$ ) of COVID-19 cases in Greece $(r=-0.677, p=0.031$ and $r=-0.789, p=0.001$, respectively). There was also a significant positive correlation between the number of national COVID-19 cases and the per- centage of HTN as diagnosis on admission among the number of total incidents during the start of the pandemic in Greece (from Feb $26^{\text {th }}$ to April $2^{\text {nd }}$, 2020) $(r=0.82$, lag 7 days, $p=0.045)$.

\section{Discussion}

The main finding of the present study is the significant reduction in the absolute number of visiting patients presenting with HTNu after the spread of SARS-CoV-2 in Greece. This trend appeared to reverse later, when the pandemic in the country started to decrease (Figure 3). This U-shaped pat- 
I. Leontsinis, V. Papademetriou, C. Chrysohoou, M. Kariori, I. Dalakouras, P. Tolis, C. Fragoulis, T. Kalos, F.P. Tatakis, K. Dimitriadis, M. Doumas, H. Sambatakou, M. Pirounaki, C. Mihas, N. Katsiki, S. Bhaskar, G. Tsivgoulis, D. Tousoulis, M. Banach, K. Tsioufis
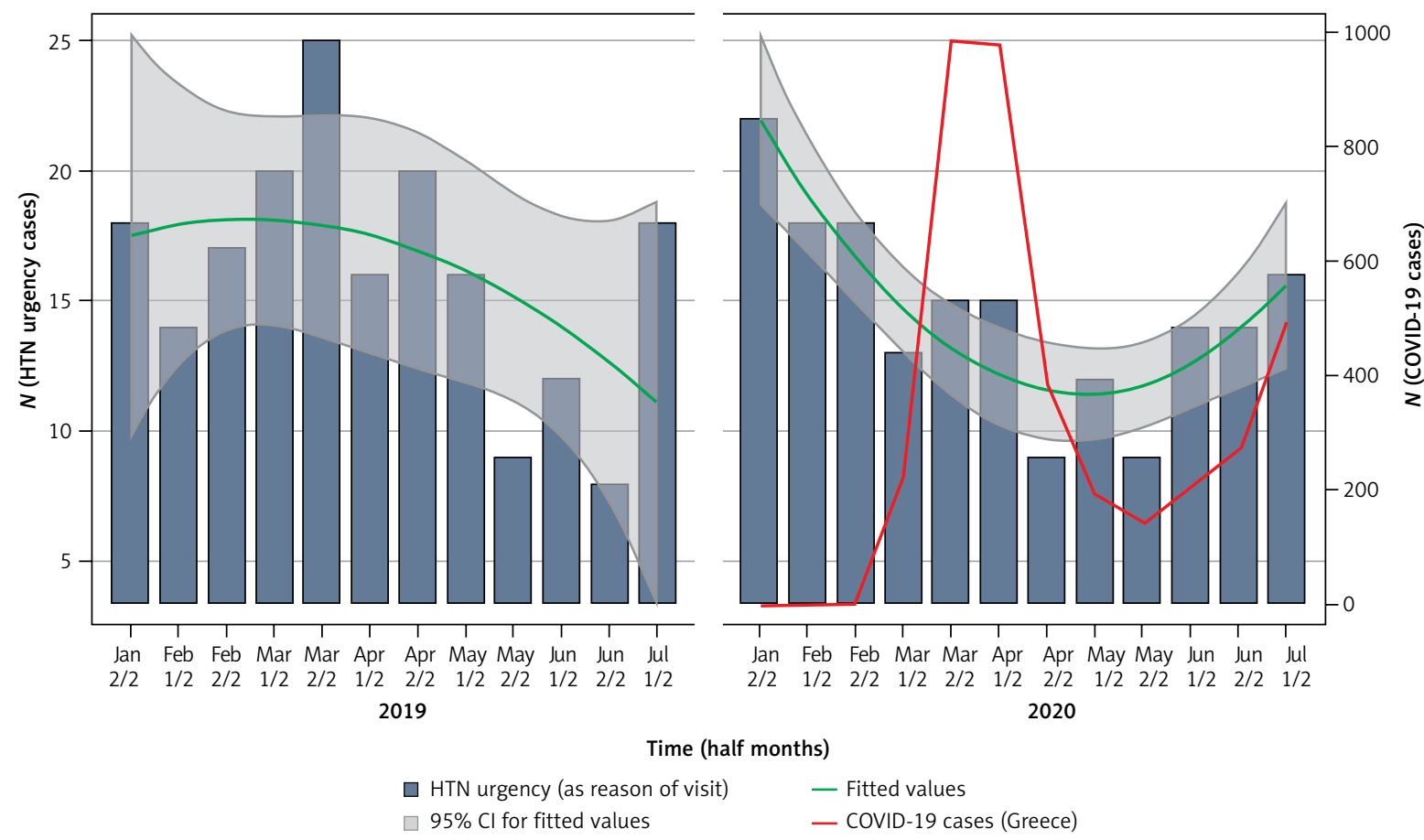

$\begin{array}{ll}\square \text { HTN urgency (as reason of visit) } & - \text { Fitted values } \\ \square 95 \% \mathrm{Cl} \text { for fitted values } & - \text { COVID-19 cases (Greece) } \\ \text { Graphs by year. } & \end{array}$

Figure 3. Hypertension (HTN) urgency (as reason of visit) cases trend by half-month periods in 2019 and 2020 COVID-19 cases in Greece are also shown with the red line in the 2020 graph

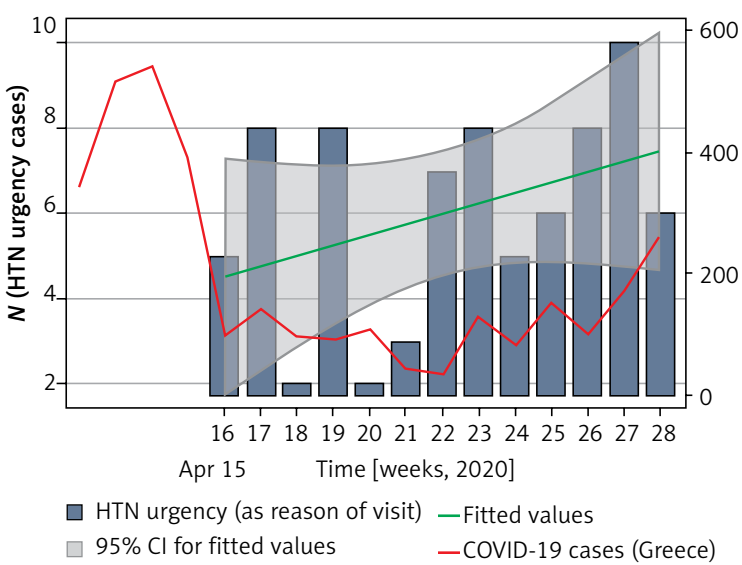

Figure 4. Linear increasing trend of hypertension (HTN) urgency cases (as reason of visit) and COVID-19 cases in Greece by week time periods in 2020, after the reduction of the COVID-19 cases

tern of HTNu followed a similar trend to all-cause attendance in the ECD during the pandemic expansion (Figure 2). In contrast, HTNu cases in 2019 showed a continuous declining trend inversely related to the environmental temperature increase, which could reflect the principle of seasonal BP variability [24].

The phenomenon of a reduced visit rate to the emergency department for cardiovascular causes has already been discussed by our team during the first months of the COVID-19 pandemic [2], as well as by other investigators [25, 26]. In accordance, visits for specific cardiovascular emergencies, such as acute stroke or myocardial infarction
(MI), have similarly decreased during the virus spread [3-5, 27-29]. Most of the authors attribute this trend to the fear of potential contagion, ॐै leading patients suffering from relevant events not to report to the emergency department. Additionally, the imposed restrictive measures on transportation, the local or national lockdowns $z$ and the regional campaigns promoting self-isolation have been suggested to increase the levels of stress and prevent part of the population from visiting the emergency department. The latter is further supported in our study by the increased relative frequency of all-cause admissions during the study period. It can be speculated that patients with less severe events avoided contacting the emergency department, whereas those patients visiting the emergency room were more likely to be admitted. The later increase in HTNu cases could represent hypertensive events that were neglected during the restrictive period, and the patients were not transferred to the emergency department. Interestingly, the number of HTNu visits started to increase before the cancellation of the lockdown measures, which happened on the $4^{\text {th }}$ of May in Greece (Figure 4). The U-shaped curve appeared when the epidemic curve of new COVID-19 cases started to flatten. The ascending part of the U-shaped curve was observed only when the daily cases of COVID-19 stabilized to a low level, whereas the restrictive measures were still valid, suggesting that the sudden and violent spread of the virus had a more profound 
impact on stressing the public than the restrictive measures themselves.

Another explanatory approach could link the duration of the stressful stimulus (i.e., the COVID-19 threat) with the late increasing trend of the absolute number of HTNu cases. Accumulated stress could result in higher BP levels. The stressful condition of a HTNu or HTNe could overcome the weakened, over time, fear of contagion and lead more patients to seek medical advice, explaining the increasing HTN-related admissions during the ascending part of the U-shaped curve. This hypothesis is further strengthened by evidence that highlights the significant impact of the pandemic on mental health. Increased levels of anxiety, prevalence of depression, stress and insomnia have been attributed to the virus spread, which appeared to affect all the population. The largest impact was documented on infected patients and their relatives, followed by health workers and patients with chronic illnesses. Nevertheless, the general public has been affected too $[30,31]$. Female gender, social isolation, low socio-economic status and the presence of chronic diseases, known to be related to a higher risk of severe COVID-19 infection, have all been presented as risk factors predisposing to increased levels of anxiety and depression related to the pandemic [30]. Interestingly, our results demonstrated women to have a higher rate of all-cause visits during the study period in 2020 compared with the previous year. This could be related to the aforementioned impact on mental health; however, our study does not include the necessary data to support it.

Based on retrospective epidemiological data, HTN was presented as a risk factor for increased susceptibility to COVID-19, increased disease severity and unfavorable outcomes [6-14]. Undoubtedly, this information made hypertensive patients feel vulnerable. In the meantime, the recognition of angiotensin-converting enzyme 2 (ACE2) as the facilitator of SARS-CoV-2 entry in humans $[32,33]$ raised significant concerns about the appropriateness of RAS blocker usage [15]. Theoretically, RAS blocker-induced ACE2 upregulation could predispose to an increased likelihood for or severity of a coronavirus infection. An opposing theory suggested that RAS inhibition could ameliorate the inflammatory cascade [16]. Consequently, both health workers and the public were confused about HTN treatment due to its potential effect on COVID-19 transmission and severity [34]. The first hypothesis prompted some of its supporters to advise against the initiation or continuation of this drug category during the pandemic [17, 3537]. This practice was challenged in the light of insufficient evidence [34, 38-43]. Several scientific societies recommended against it, extenuating the preceding confusion regarding this corner- stone treatment which extends beyond HTN. Subsequent observational data suggested that HTN could not independently predict disease severity [41, 44-46] and also that RAS blocker usage could not influence the propensity to coronavirus or worse outcomes [15, 44, 47-50]. In contrast, HTN control with RAS inhibition in the COVID-19 cases may favor the prognosis [42, 51-55]. However, it is possible that a part of the hypertensive population discontinued such medications in the fear of possible complications. This would have also led to the observed early increased rate of HTN admissions and the late increase in HTNu visits.

In Greece, the Hellenic Society of Cardiology initiated a national awareness campaign to promote cardiovascular prevention and treatment policies in the COVID-19 era, initiated in mid-March 2020. In our study results, the HTNu cases started to increase 1 month after the implementation of the campaign. It is highly likely that this campaign itself may have affected people's perspective in relation to HTN management. In combination with the virus spread interception, this may have also contributed to the ascending part of the U-shaped curve of our results. Similar findings were reported regarding stroke admission rates in the Greater Manchester and East Cheshire area [56]. Although stroke admission rates were reported to decline during the first wave of the pandemic [56-62], Gittins et al. demonstrated that this reduction was partially reversed after the imposition of a stroke awareness campaign [56].

However, untreated HTNu can progress to HTNe conditions. Unattended, severe HTNu patients could later suffer from an acute stroke. Hypothetically, in such events, these patients would be transferred to stroke-dedicated centers, bypassing the ECD, explaining part of the "missing" HTNu visits in our results. On the other hand, the later increase in stroke admission rate in the Gittins et al. study [55] could reflect untreated HTNu cases, leading to a stroke. Additionally, atrial fibrillation (AF) is a well-known cause of stroke, and uncontrolled HTN increases its incidence. Regional lockdowns have been associated with a reduced incidence of AF diagnosis, raising concerns about the detrimental implications of unattended cases [63]. On a theoretical basis, unattended HTNu cases could impact on more AF events and subsequently increased stroke incidence. Nevertheless, COVID-19 could have also influenced the stroke admission rates as the disease per se has been associated with increased stroke incidence [64-66].

Outpatient HTN care faced profound disturbance due to the restricting measures and social distancing. The ESH reported a significant decline to the number of hypertensive patients evaluated or treated in excellence centers, reaching the percentage of $90 \%$ during the complete lockdown 
I. Leontsinis, V. Papademetriou, C. Chrysohoou, M. Kariori, I. Dalakouras, P. Tolis, C. Fragoulis, T. Kalos, F.P. Tatakis, K. Dimitriadis, M. Doumas, H. Sambatakou, M. Pirounaki, C. Mihas, N. Katsiki, S. Bhaskar, G. Tsivgoulis, D. Tousoulis, M. Banach, K. Tsioufis

period [17]. The same disruption occurring simultaneously with the lockdown in Greece may have also influenced the increase in HTNu visits after April $15^{\text {th }}, 2020$. Our hospital covers a large urban area in which HTN management is being practiced in outpatient clinics, either public or private. The government offered the opportunity of renewing prescriptions for chronic illnesses, including antihypertensive medications via virtual (over the phone) consultations. However, the available infrastructure and personnel were not adequate to accommodate all needs, and telemedicine, although helpful [67], was not technically feasible in most cases. The pandemic presented a big challenge for both the public and health care professionals and took a considerable length of time to adopt. Consequently, from our experience, there was a significant disturbance in HTN management which in any case mandates the presence of an integral, dedicated and focused health care system. This would have also contributed to the increased relative frequency of HTNu cases during all the studied period compared with 2019.

A rather interesting finding was that the ratio of attendance for HTNu/all visits in the period with the least total attendance (last 2 weeks of March 2020, Figure 2) was actually increased and was significantly higher than the corresponding ratio for 2019. We could suggest that this result may reflect an actual increase in BP levels, leading to proportionally more frequent events of HTNu. A similar trend in BP values was described after disasters such as the 2011 earthquake in Japan and has been labeled as "disaster HTN" [68-71]. Although our study sample could not be considered sufficient to conclude whether a "disaster HTN" effect was present in the global threat of COVID-19, this theory could explain the early increase in the relative frequency of HTN diagnosis.

We acknowledge that comparing more than one of the preceding years with the studied period would offer added value to our results. Another limitation of our study is that our data do not include the necessary information to present the trends of HTNe cases during the studied period as many of these cases may have been registered under other diagnoses, such as MI or acute heart failure. In the same line, our ECD does not receive stroke referrals, which account for a remarkable percentage of HTNe cases. Moreover, part of the reduction in HTNu cases could represent patients who selected an alternative health care provider. However, our hospital was not dedicated to hospitalized COVID-19 cases and it was considered to be among the safe ones during the studied period. On the other hand, the number of HTN diagnoses on admission could reflect the incidence of HTN emergencies. The acceptance of such an assump- tion would indicate that HTN emergencies were probably increased during the studied period but we cannot support it adequately.

To the best of our knowledge, the present study is the first to evaluate the impact of COVID-19 on the incidence of HTNu in an emergency department. Our results highlight the profound difference in population behavior towards HTNu during the first wave of the pandemic which seems to be severely affected by the coronavirus spread and to a lesser extent by the implementation of restrictive measures. The observed relative increase of hypertension related admissions raises concerns that overall hypertension control was significantly affected during the studied period.

Taking into consideration the anticipated subsequent phases of the pandemic and based on our observations, we could suggest several measures to avoid similar disturbance in hypertension care. Hypertension clinics' regular operation needs to be restored with all the necessary protective measures available. Telemedicine applications together with over the phone consultations on a daily basis including out of hours service could provide reliable help to hypertensive subjects who prefer to avoid direct visits. Informative campaigns about the prompt screening, monitoring and hypertension treatment are of high value in order to keep the public alert about the potential dangers of neglecting uncontrolled blood pressure levels.

In conclusion, HTNu in absolute numbers followed a U-shaped curve, similar to other cardiovascular conditions, during the first wave of the COVID-19 pandemic, in terms of ECD attendance in a tertiary General Hospital in Athens, Greece. Stress in combination with the disrupted HTN outpatient care system and the impact of the national campaign to clarify potential misconceptions about HTN management seem to be the main contributors of these findings. Uncontrolled HTN can provoke a domino effect in cardiovascular mortality and morbidity, increasing the incidence of disabling events such as stroke or MI. Furthermore, untreated HTN is linked to unfavorable COVID-19 outcomes. A well-structured system for outpatient HTN management is of great value, which, in the context of the continuously growing pandemic, needs to integrate urgently with applications of telemedicine to offer a safe follow-up in the patients' safe environment.

\section{Conflict of interest}

The authors declare no conflict of interest.

\section{References}

1. The impact of the COVID-19 pandemic on noncommunicable disease resources and services: results of a rapid assessment. Geneva: World Health Organization; 2020 
2. Tsioufis K, Chrysohoou C, Kariori M, et al. The mystery of 'missing' visits in an emergency cardiology department, in the era of COVID-19: a time-series analysis in a tertiary Greek General Hospital. Clin Res Cardiol 2020; 109: 1483-9.

3. Papafaklis MI. Missing' acute coronary syndrome hospitalizations during the COVID-19 era in Greece: Medical care avoidance combined with a true reduction in incidence? Clin Cardiol 2020; 43: 1142-9.

4. Vacanti G, Bramlage P, Schymik G, et al. Reduced rate of admissions for acute coronary syndromes during the COVID-19 pandemic: an observational analysis from a tertiary hospital in Germany. Herz 2020, doi: 10.1007/ s00059-020-04991-3.

5. Seiffert M, Brunner FJ, Remmel M, et al. Temporal trends in the presentation of cardiovascular and cerebrovascular emergencies during the COVID-19 pandemic in Germany: an analysis of health insurance claims. Clin Res Cardiol 2020; 109: 1540-8.

6. Guan W, Ni ZY, Hu Y, et al. Clinical characteristics of coronavirus disease 2019 in China. N Engl J Med 2020; 382: 1708-20.

7. Zhou F, Yu T, Du R, et al. Clinical course and risk factors for mortality of adult inpatients with COVID-19 in Wuhan, China: a retrospective cohort study. Lancet 2020; 395: 1054-62.

8. Chen N, et al. Epidemiological and clinical characteristics of 99 cases of 2019 novel coronavirus pneumonia in Wuhan, China: a descriptive study. Lancet 2020; 395: 507-13.

9. Wang D, Hu B, Hu C, et al. Clinical characteristics of 138 hospitalized patients with 2019 novel coronavirusinfected pneumonia in Wuhan, China. JAMA 2020; 323: 1061-9.

10. Wu C, Chen X, Cai Y, et al. risk factors associated with acute respiratory distress syndrome and death in patients with coronavirus disease 2019 pneumonia in Wuhan, China. JAMA Intern Med 2020; 180: 934-43.

11. Yang J, Zheng Y, Gou X, et al. Prevalence of comorbidities and its effects in patients infected with SARS-CoV-2: a systematic review and meta-analysis. Int J Infect Dis 2020; 94: 91-5.

12. Richardson S, Hirsch JS, Narasimhan M, et al. Presenting characteristics, comorbidities, and outcomes among 5700 patients hospitalized with COVID-19 in the New York City area. JAMA 2020; 323: 2052-9.

13. Lippi G, Wong J, Henry BM. Hypertension and its severity or mortality in Coronavirus disease 2019 (COVID-19): a pooled analysis. Pol Arch Intern Med 2020; 130: 304-9.

14. Wang B, Li R, Lu Z, Huang Y. Does comorbidity increase the risk of patients with COVID-19: evidence from meta-analysis. Aging 2020; 12: 6049-57.

15. Li G, Hu R, Zhang X. Antihypertensive treatment with ACEI/ARB of patients with COVID-19 complicated by hypertension. Hypertens Res 2020; 43: 588-90.

16. Schiffrin EL, Flack JM, Ito S, Muntner P, Webb RC. Hypertension and COVID-19. Am J Hypertens 2020; 33: 373-74.

17. Kreutz R, Dobrowolski P, Prejbisz A, et al. Lifestyle, psychological, socioeconomic and environmental factors and their impact on hypertension during the coronavirus disease 2019 pandemic. J Hypertens 2021; 39: 107789.

18. Astarita A, Covella M, Vallelonga F, et al. Hypertensive emergencies and urgencies in emergency departments: a systematic review and meta-analysis. J Hypertens 2020; 38: 1203-10.
19. Angeli F, Reboldi G, Verdecchia P. Hypertensive urgencies and emergencies: misconceptions and pitfalls. Eur J Intern Med 2020; 71: 15-7.

20. Williams B, Mancia G, Spiering W, et al. 2018 ESC/ESH Guidelines for the management of arterial hypertension. Eur Heart J 2018; 39: 3021-104.

21. Muiesan ML, Salvetti M, Amadoro V, et al. An update on hypertensive emergencies and urgencies. J Cardiovasc Med 2015; 16: 372-82.

22. Saladini F, Mancusi C, Bertacchini F, et al. Diagnosis and treatment of hypertensive emergencies and urgencies among Italian emergency and intensive care departments. Results from an Italian survey: Progetto GEAR (Gestione dell'Emergenza e urgenza in ARea critica). Eur J Intern Med 2020; 71: 50-6.

23. Papadopoulos DP, Mourouzis I, Thomopoulos C, Makris T, Papademetriou V. Hypertension crisis. Blood Press 2010; 19: 328-36.

24. Fares A. Winter hypertension: potential mechanisms. Int J Health Sci 2013; 7: 210-9.

25. Franchini S, Spessot M, Landoni G, et al. Stranger months: how SARS-CoV-2, fear of contagion, and lockdown measures impacted attendance and clinical activity during February and March 2020 at an urban Emergency Department in Milan. Disaster Med Public Health Prep 2020; 15: e33-42.

26. Oikonomou E, Aznaouridis K, Barbetseaa J, et al. Hospital attendance and admission trends for cardiac diseases during the COVID-19 outbreak and lockdown in Greece. Public Health 2020; 187: 115-9.

27. Mafham MM, Spata E, Goldacre R, et al. COVID-19 pandemic and admission rates for and management of acute coronary syndromes in England. Lancet 2020; 396: 381-9.

28. Scholz KH, Lengenfelder B, Thilo C, et al. Impact of COVID-19 outbreak on regional STEMI care in Germany. Clin Res Cardiol 2020; 109: 1511-21.

29. Tam CCF, Cheung KS, Lam S, et al. Impact of coronavirus disease 2019 (COVID-19) outbreak on ST-segment-elevation myocardial infarction care in Hong Kong, China. Circ Cardiovasc Qual Outcomes 2020; 13: e006631.

30. Salari N, Hosseinian-far A, Jalali R, et al. Prevalence of stress, anxiety, depression among the general population during the COVID-19 pandemic: a systematic review and meta-analysis. Glob Health 2020; 16: 57.

31. Luo M, Guo L, Yu M, Jiang W, Wang H. The psychological and mental impact of coronavirus disease 2019 (COVID-19) on medical staff and general public - a systematic review and meta-analysis. Psychiatry Res 2020; 291: 113190

32. Wrapp D, Wang N, Corbett KS, et al. Cryo-EM structure of the 2019-nCoV spike in the prefusion conformation. Science 2020; 367: 1260-3.

33. Hoffmann M, Kleine-Weber $H$, Schroeder S, et al. SARSCoV-2 cell entry depends on ACE2 and TMPRSS2 and is blocked by a clinically proven protease inhibitor. Cell 2020; 181: 271-80.e8.

34. Vaduganathan M, Vardeny $\mathrm{O}$, Michel T, McMurray JJV, Pfeffer MA, Solomon SD. Renin-angiotensin-aldosterone system inhibitors in patients with Covid-19. N Engl J Med 2020; 382: 1653-9.

35. Fang L, Karakiulakis G, Roth M. Are patients with hypertension and diabetes mellitus at increased risk for COVID-19 infection? Lancet Respir Med 2020; 8: e21.

36. Kulkarni S, Jenner BL, Wilkinson I. COVID-19 and hypertension. J Renin Angiotensin Aldosterone Syst 2020; 21 : 147032032092785 . 
I. Leontsinis, V. Papademetriou, C. Chrysohoou, M. Kariori, I. Dalakouras, P. Tolis, C. Fragoulis, T. Kalos, F.P. Tatakis, K. Dimitriadis, M. Doumas, H. Sambatakou, M. Pirounaki, C. Mihas, N. Katsiki, S. Bhaskar, G. Tsivgoulis, D. Tousoulis, M. Banach, K. Tsioufis

37. Esler M, Esler D. Can angiotensin receptor-blocking drugs perhaps be harmful in the COVID-19 pandemic? J Hypertens 2020; 38: 781-2.

38. Rico-Mesa JS, White A, Anderson AS. Outcomes in patients with COVID-19 infection taking ACEI/ARB. Curr Cardiol Rep 2020; 22: 31.

39. Danser AHJ, Epstein M, Batlle D. Renin-Angiotensin system blockers and the COVID-19 pandemic: at present there is no evidence to abandon renin-angiotensin system blockers. Hypertension 2020; 75: 1382-5.

40. Kreutz R, El-Hady Algharably EA, Azizi M, et al. Hypertension, the renin-angiotensin system, and the risk of lower respiratory tract infections and lung injury: implications for COVID-19. Cardiovasc Res 2020; 116: 1688-99.

41. Tadic M, Cuspidi C, Grassi G, Mancia G. COVID-19 and arterial hypertension: hypothesis or evidence? J Clin Hypertens 2020; 22: 1120-6.

42. Katsiki N, Banach M, Mikhailidis D. Lipid-lowering therapy and renin-angiotensin-aldosterone system inhibitors in the era of the COVID-19 pandemic. Arch Med Sci 2020; 16: 485-9.

43. Cismaru AC, Cismaru LG, Nabavi SF, et al. Game of 'crowning' season 8: RAS and reproductive hormones in COVID-19 - can we end this viral series? Arch Med Sci 2021; $17: 275-84$

44. laccarino G, Grassi G, Borghi C, et al. Age and multimorbidity predict death among COVID-19 patients: results of the SARS-RAS Study of the Italian Society of Hypertension. Hypertension 2020; 76: 366-72.

45. Shibata S, Arima H, Asayama K, et al. Hypertension and related diseases in the era of COVID-19: a report from the Japanese Society of Hypertension Task Force on COVID-19. Hypertens Res 2020; 43: 1028-46.

46. Drager LF, Pio-Abreu A, Lopes RD, Bortolotto LA. Is hypertension a real risk factor for poor prognosis in the COVID-19 pandemic? Curr Hypertens Rep 2020; 22: 43.

47. Huang Z, Cao J, Yao Y, et al. The effect of RAS blockers on the clinical characteristics of COVID-19 patients with hypertension. Ann Transl Med 2020; 8: 430.

48. Sinha S, Sehgal A, Sehgal R. Association of ACE2 receptor and ACEIs/ARBs with disease severity in COVID-19. Drug Discov Ther 2020; 14: 161-70.

49. Reynolds HR, Adhikari S, Pulgarin C, et al. Renin-angiotensin-aldosterone system inhibitors and risk of Covid-19. N Engl J Med 2020; 382: 2441-8.

50. Mancia G, Rea F, Ludergnani M, Apolone G, Corrao G. Renin-angiotensin-aldosterone system blockers and the risk of Covid-19. N Engl J Med 2020; 382: 2431-40.

51. Zhang P, Zhu L, Cai J, et al. Association of inpatient use of angiotensin-converting enzyme inhibitors and angiotensin II receptor blockers with mortality among patients with hypertension hospitalized with COVID-19. Circ Res 2020; 126: 1671-81.

52. Meng J, Xiao G, Zhang J, et al. Renin-angiotensin system inhibitors improve the clinical outcomes of COVID-19 patients with hypertension. Emerg Microbes Infect 2020; 9: 757-60.

53. Wang Y, Chen B, Li Y, et al. The use of renin-angiotensin-aldosterone system (RAAS) inhibitors is associated with a lower risk of mortality in hypertensive COVID-19 patients: a systematic review and meta-analysis. J Med Virol 2021; 93: 1370-77.

54. Yang G, Tan Z, Zhou L, et al. Effects of angiotensin II receptor blockers and ACE (angiotensin-converting enzyme) inhibitors on virus infection, inflammatory status, and clinical outcomes in patients with COVID-19 and hypertension. A single-center retrospective study. Hypertension 2020; 76: 51-8.

55. Momtazi-Borojeni AA, Banach M, Reiner Z, et al. Interaction between coronavirus S-protein and human ACE2: hints for exploring efficient therapeutic targets to treat COVID-19. Angiology 2021; 72: 122-30.

56. Gittins M, Ashton C, Holden N, et al. Environmental factors and hyperacute stroke care activity during the COVID-19 pandemic: an interrupted time-series analysis. J Stroke Cerebrovasc Dis 2020; 29: 105229.

57. Meza HT, Gil AL, Saldana AS, et al. Impact of COVID-19 outbreak on ischemic stroke admissions and in-hospital mortality in North-West Spain. Int J Stroke 2020; 15 755-62

58. Padmanabhan N, Natarajan I, Gunston R, Raseta M, Roffe C. Impact of COVID-19 on stroke admissions, treatments, and outcomes at a comprehensive stroke centre in the United Kingdom. Neurol Sci 2021; 42: 15-20.

59. Bersano A, Kraemer M, Touzé E, et al. Stroke care during the COVID-19 pandemic: experience from three large European countries. Eur J Neurol 2020; 27: 1794-800.

60. Bullrich MB, Fridman S, Mandzia JL, et al. COVID-19: stroke admissions, emergency department visits, and prevention clinic referrals. Can J Neurol Sci J Can Sci Neurol 2020; 47: 693-6.

61. Montaner J. Break in the stroke chain of survival due to COVID-19. Stroke 2020; 51: 2307-314.

62. Jasne AS, Chojecka P, Maran I, et al. Stroke code presen tations, interventions, and outcomes before and during the COVID-19 pandemic. Stroke 2020; 51: 2664-73.

63. Holt $A$, Gislason $G H$, Schou $M$, et al. New-onset atrial fibrillation: incidence, characteristics, and related events following a national COVID-19 lockdown of 5.6 million people. Eur Heart J 2020; 41: 3072-9.

64. Tan YK, Goh C, Leow AST, et al. COVID-19 and ischemic stroke: a systematic review and meta-summary of the literature. J Thromb Thrombolysis 2020; 50: 587-95.

65. Ellul MA, Benjamin L, Singh B, et al. Neurological associations of COVID-19. Lancet Neurol 2020; 19: 767-83.

66. Fatima N, Saqqur M, Qamar F, Shaukat S, Shuaib A. Impact of COVID-19 on neurological manifestations: an overview of stroke presentation in pandemic. Neurol Sci 2020; 41: 2675-9.

67. Bhaskar S, Bradley S, Chattu VK, et al. Telemedicine as the New Outpatient Clinic Gone Digital: Position Paper From the Pandemic Health System REsilience PROGRAM (REPROGRAM) International Consortium (Part 2). Front Public Health 2020; 8: 410.

68. Kario K. Disaster hypertension. Circ J 2012; 76: 553-62.

69. Piscoya A, Ng-Sueng LF, Parra Del Riego A, et al. Efficacy and harms of convalescent plasma for treatment of hospitalized COVID-19 patients: a systematic review and meta-analysis. Arch Med Sci 2021; 17: 1251-61.

70. Lewek J, Jatczak-Pawlik I, Maciejewski M, Jankowski P, Banach M. COVID-19 and cardiovascular complications - preliminary results of the LATE-COVID study. Arch Med Sci 2021; 17: 818-22.

71. Banach M, Burchardt P, Chlebus K, et al. PoLA/CFPiP/ PCS/PSLD/PSD/PSH guidelines on diagnosis and therapy of lipid disorders in Poland 2021. Arch Med Sci 2021; 17: 1447-547. 